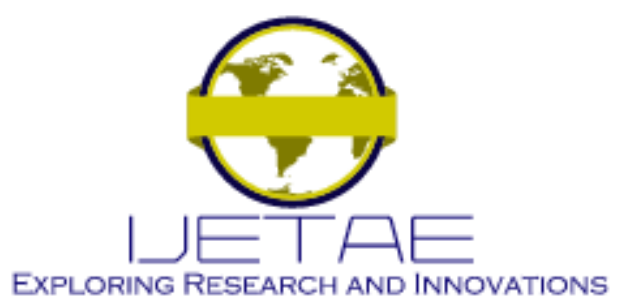

International Journal of Emerging Technology and Advanced Engineering

Website: www.ijetae.com (E-ISSN 2250-2459, Scopus Indexed, ISO 9001:2008 Certified Journal, Volume 11, Issue 12, December 2021)

Manuscript Received: 08 November 2021, Received in Revised form: 07 December 2021, Accepted: 12 December 2021 DOI: 10.46338/ijetae1221_21

\title{
Solar Powered Arduino Robot Arm: A Modeling Study
}

\author{
Çetin ÇIMEN ${ }^{1}$, Ezgi Pelin YILDIZ ${ }^{2}$ \\ ${ }^{I}$ Kafkas University Kazım Karabekir Vocational School of Technical Sciences, Department of Machinery and Metal Kars \\ Turkey. \\ ${ }^{2}$ Kafkas University Kazım Karabekir Vocational School of Technical Sciences, Department of Computer Technology
}

Kars Turkey.

\begin{abstract}
Solar energy, one of the renewable energy sources, is a solution that meets the increasing electricity consumption problem of humanity today. When the literature is examined, researches and industrial products on issues such as solar panel efficiency and obtaining maximum energy from the sun attract attention in recent years. Solar powered robot arm is an example of these industrial products. Industrial robots can be defined as machines operating in the industry, which have a certain number of axes and limbs, follow preprogrammed and taught trajectories in a reproducible manner thanks to rotational and/or sliding joints and actuators that activate these joints. Nowadays, such robot arms are used in many areas such as car making, phone production, as well as in places where human power is not enough. Industrial robot, which is an important part of the automation system the importance of arms is increasing day by day. Robots, which have recently become widespread in production systems, need to be introduced and adapted to the production systems in our country. This research a modeling study has been carried out for the production of solar powered arduino robot arm. In this context this study is an example of construction manufacturing and computer interaction. The designed 3D robot arm works on the vertical axis while moving in the horizontal plane with 4 servo motors.
\end{abstract}

Keywords - Solar panel efficiency, Arduino software, Robot arm, 3D, Modeling Study.

\section{INTRODUCTION}

The conversion of the sun's rays reaching the earth at a point that does not threaten human health into electricity with special panels is known as solar energy. In short, solar energy is defined as a renewable and clean energy source that does not cause pollution. In another source, solar energy is explained as the radiative energy released by the fusion process in the core of the sun. There are many benefits to using solar energy; it is the most abundant and clean energy in the world and it does not pollute the environment, it is noiseless.
Although solar energy has a wide variety of applications, today thermal and PV electricity come to the fore as application areas (Altuntop \& Erdemir, 2013). When the literature is examined, researches and industrial products on issues such as solar panel efficiency and obtaining maximum energy from the sun attract attention in recent years. Solar powered robot arm is an example of these industrial products.

An industrial robot is a reprogrammable, autonomous or semi-independent functional machine that assists workers with various tasks in manufacturing or is capable of working alone (De Silva, 1987). If the functions are listed; it can only perform mechanical and repetitive tasks, manipulate objects with pre-programmed movements.

In addition it can collect data, process it and enter the machine thus optimize the work. Robot applications can be seen in almost all areas of the industry, mainly automotive, electrical, electronic and mechanical (Browne, 1998).

Main reasons for using robots in industry (Nakamura, 1991):

- Reducing labor cost

- Replacing those working in dangerous and risky places

- Providing a more flexible production system

- To complete the shortage of skilled labor

- Ability to lift more loads than humans

- The ability to reach results faster than humans

- Eliminating human errors

- Minimizing quality control errors

- High flexibility of movements

- High profit

Another work area where industrial robots are minimized is robot arm construction. A robot arm is a device equipped with at least one arm, holding devices (usually forceps, suction cups or electromiclatis), pneumatic, hydraulic or electrical sensors, position and pressure sensors and information processing organs on a base (Kruthika, Rani \& Banga, 2017). 


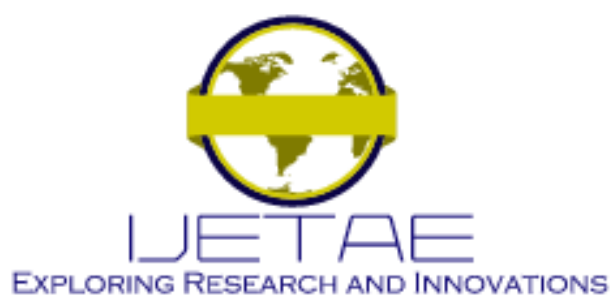

International Journal of Emerging Technology and Advanced Engineering

Website: www.ijetae.com (E-ISSN 2250-2459, Scopus Indexed, ISO 9001:2008 Certified Journal, Volume 11, Issue 12, December 2021)

Robot arms can be developed in many areas. Thanks to the robot arms, the construction of many works has been facilitated and the level of error that may arise has

When the literature is examined, it is noteworthy that there are many designs and models related to robot arms. Aydogan (2016), studied on robot arm control with a in arduino his research. The study is a modeling study. As a result, in the direction of 4 axis working with 5 servo motors a robotic arm capable of locomotion has been developed. The control of the robot arm is provided by moving the axes via android application in the "+" "_." direction. Celebi, Korkmaz, Yilmaz \& Tosun (2019), they realized the design and manufacture of 6-axis robot arm with 3D printer programming was done using Arduino software development kit. All parts were put together using bearings and screws and the production of a 6-axis robotic arm as an electro-mechanical system was successfully completed. Novita et. al (2020), they designed 3D control system of arm robot prototype for skin cancer detection. Control software was built in MATLAB GUI environment and 3D simulation adapted Peter Corke Robotics Toolbox. The system with forward kinematics movement, inverse kinematics movement, and 3D simulation features. As a result the system had worked out without any problem.

In the light of all this in this research, solar powered arduino robot arm modeling study was carried out. The design and working principles of the robot arm are explained in detail in the method parts. When the literature review is done, it has been determined that robot arm production is frequently made; but in this research, a solar panel was added to the setup. Contribution of this plugin; the solar panel converts these photons into direct current electrons thus the incoming energy is stored.

\section{METHOD}

This research is an example of a modeling study. Modeling study is a method of experimentation and application in the form of describing the behavior of the system, developing theory or hypothesis, using the established theory to predict the future behavior of the system (Cresswell \& Cresswell, 2017). This product is a modeling study and its advanced version is preferred in areas such as car making, phone making and similar uses.

\section{HARDWARE ANALYSIS}

If the machinery and equipment used in the development of this product are listed:

- 5V Solar Panel

- 3500 Amp Battery

- 2 Joysticks

- 1 Ardunio Uno Card

- 4 servo motors

- 3D Robot Arm Kit

- Jumper Cable

- Power Cable

- 5V Sensor Shield

The designed 3D robot arm works on the vertical axis while moving in the horizontal plane with 4 servo motors. Servo motor consists of a DC Motor, a gear system, a position sensor and a control circuit. DC motors are powered by a battery and run at high speed and low torque (Bozkurt, 2016). Gear and shaft assembly connected to DC motors reduce this speed to sufficient speed and higher torque.

In this prototype, servo motors are used in the joints of the robot arm. On the control arm, there are potentiometers at the joints. The potentiometer in one joint has controled the servo motor in the same joint in the robot arm.

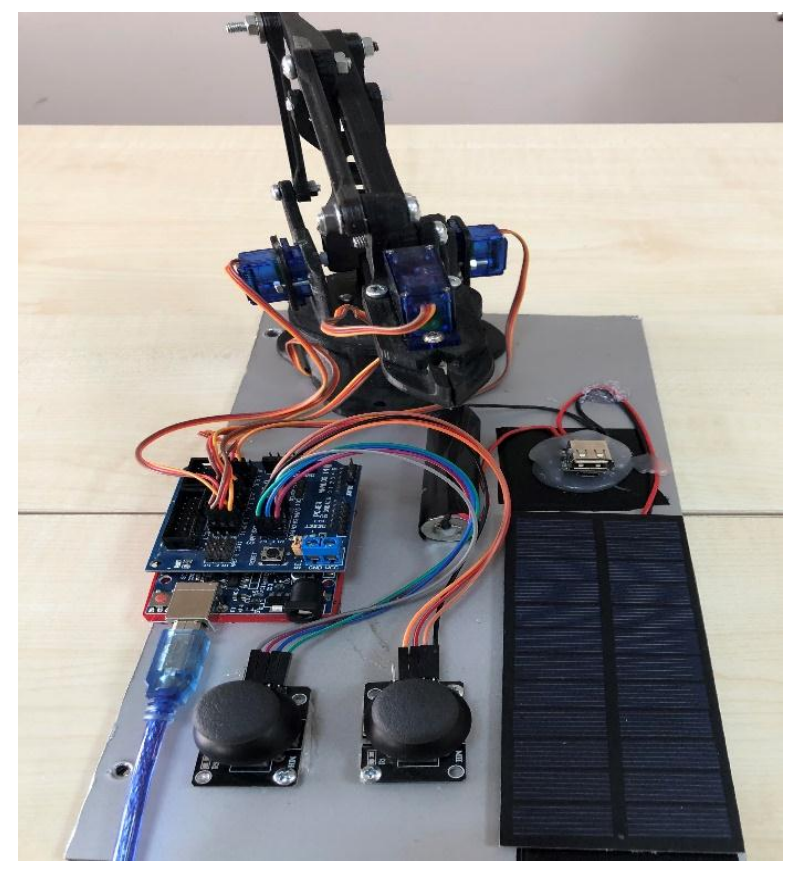

Figure 1. Solar Powered Arduino Robot Arm Prototype 


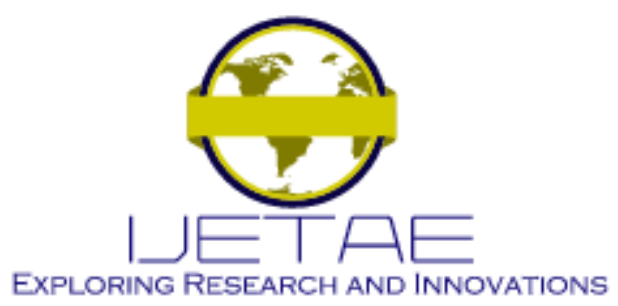

International Journal of Emerging Technology and Advanced Engineering

Website: www.ijetae.com (E-ISSN 2250-2459, Scopus Indexed, ISO 9001:2008 Certified Journal, Volume 11, Issue 12, December 2021)

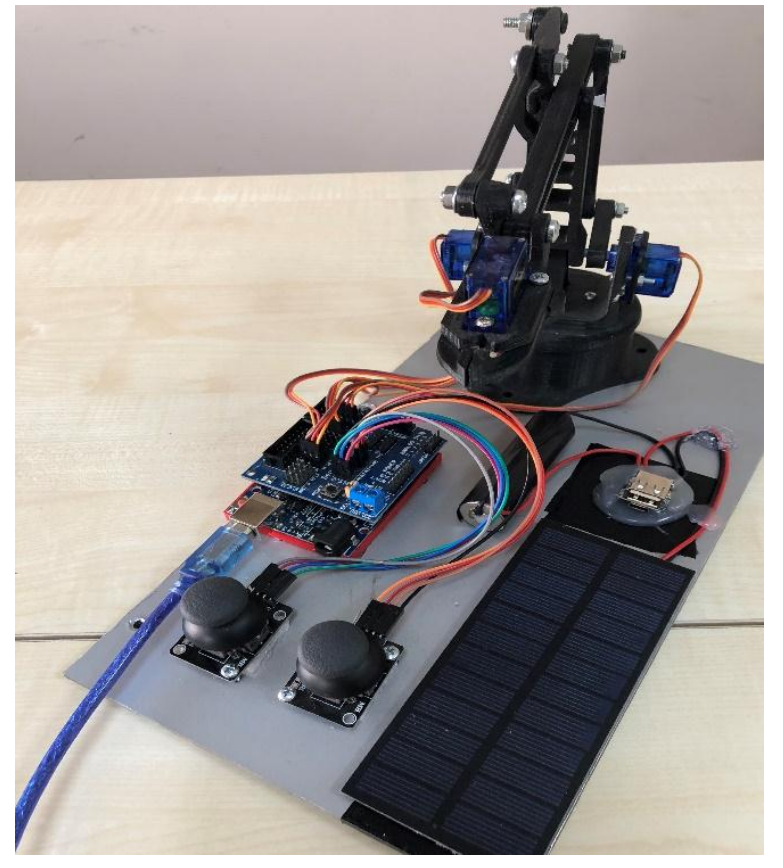

Figure 2. Solar Powered Arduino Robot Arm Prototype

\section{WORKING PRINCIPLE AND CODE SYSTEM}

If the construction phase will be explained step by step:

- First connect the joystick module to Arduino

- The connections for the joystick module and Arduino are as follows:

- GND, VCC, SIGNAL servo motor on the Sensor Shield is connected.

- GND pin on joystick module connects with GND on Sensor Shield.

- Connects VRX pin on joystick module with A0 on Sensor Shield.

- VRY pin on joystick module connects with A1 on Sensor Shield.

- Connect VCC pin on joystick module to VCC on Sensor Shield.
- When the joystick module moves horizontally or vertically, it gives values from 0 to 1023 . The servo motors will move if the value is less than 300 or greater than 700 .

- When the joystick is moved in the horizontal direction, the first servo will move to the right or left, and when the joystick is moved in the vertical direction, the second servo will move to the right or left.

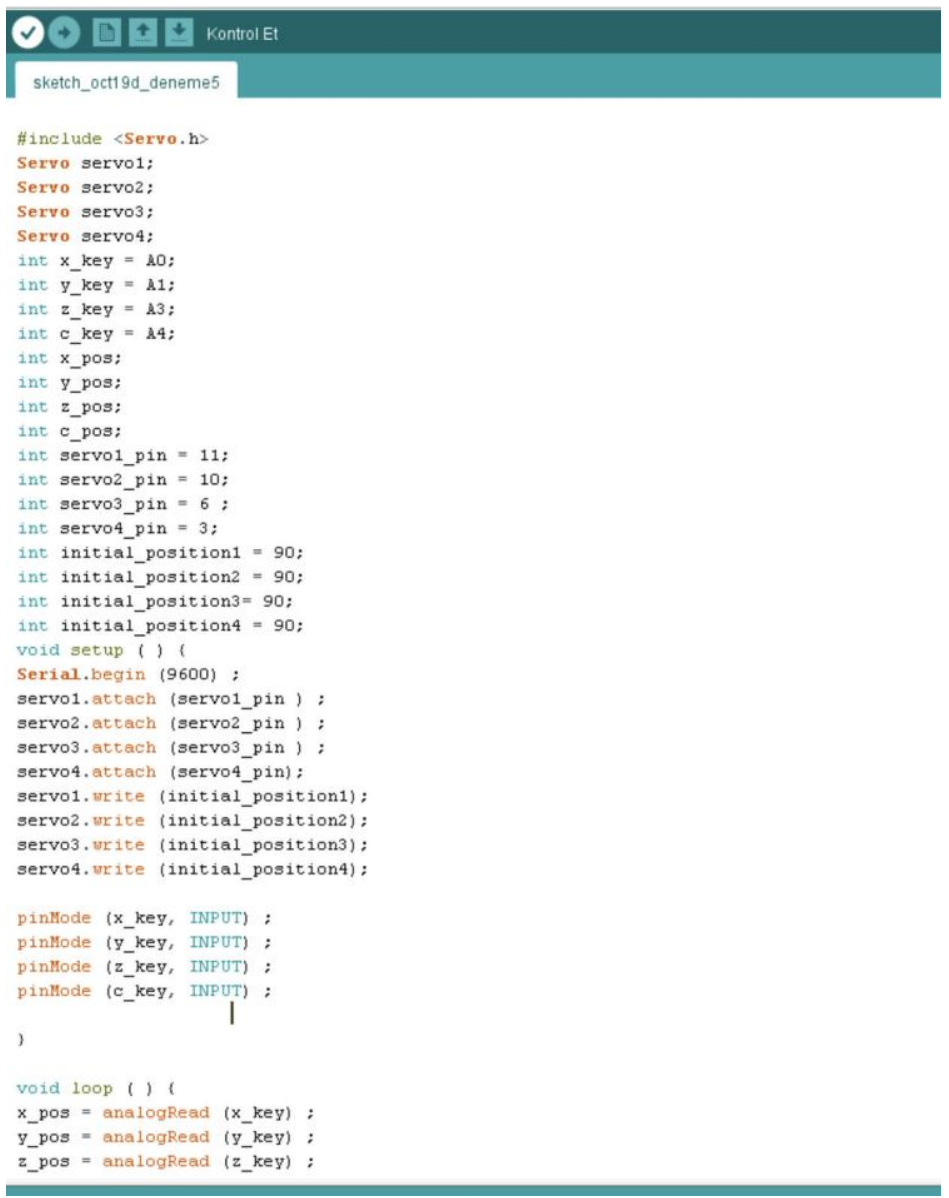

Figure 3. Ardunio Sensor Shield V5.0 Model 


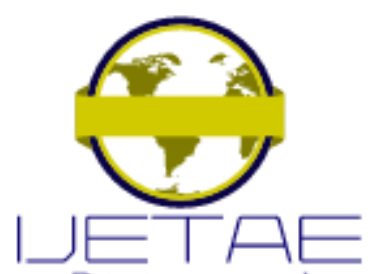

EXPLORING RESEARCH AND INNOVATIONS

International Journal of Emerging Technology and Advanced Engineering

Website: www.ijetae.com (E-ISSN 2250-2459, Scopus Indexed, ISO 9001:2008 Certified Journal, Volume 11, Issue 12, December 2021)

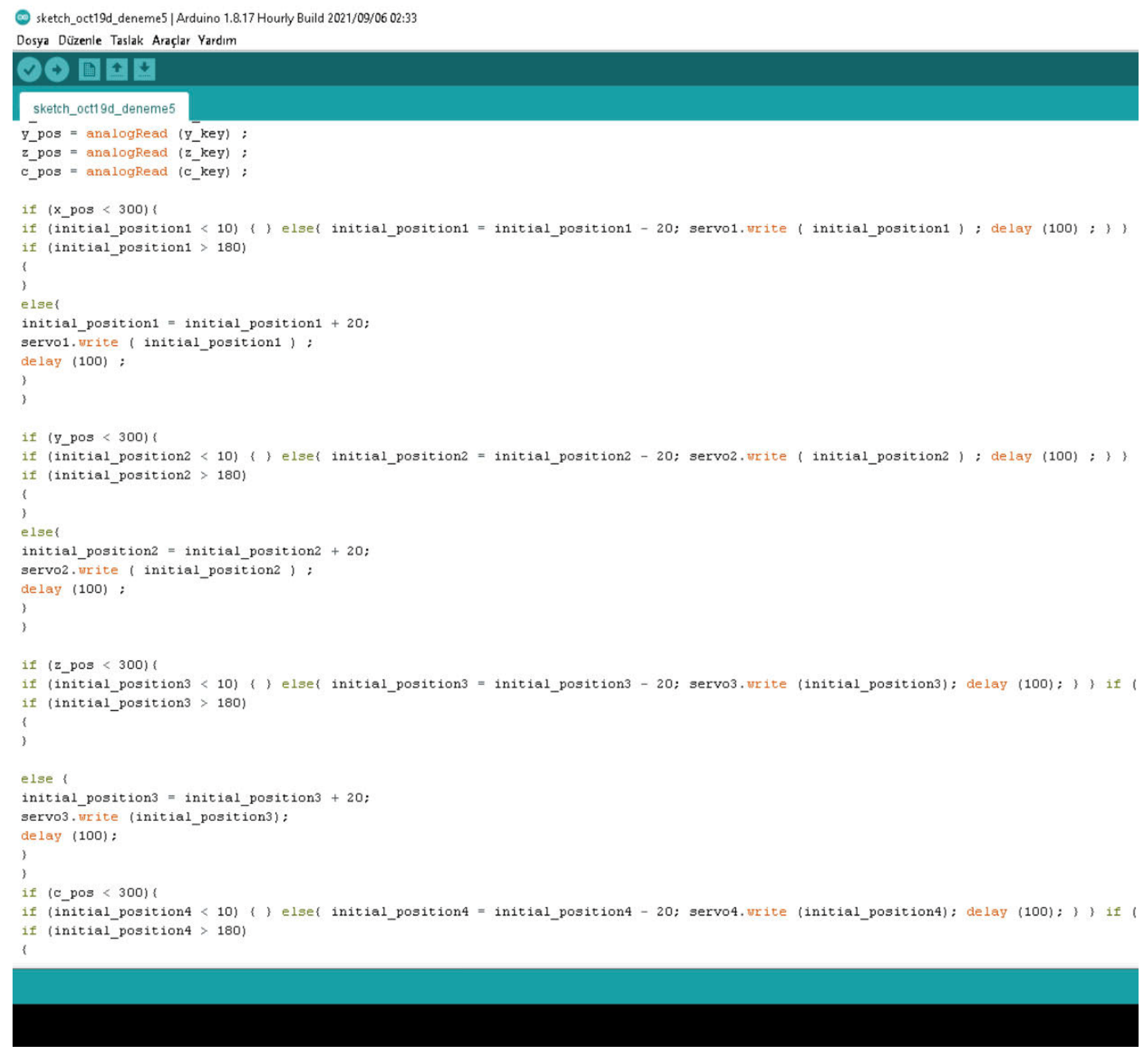




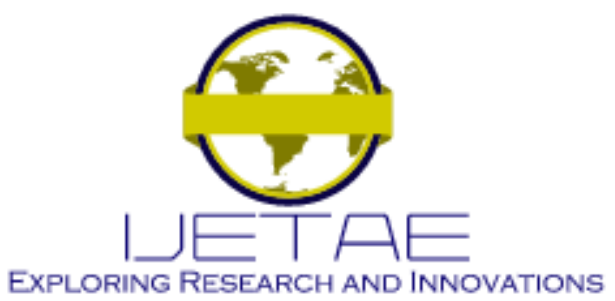

International Journal of Emerging Technology and Advanced Engineering

Website: www.ijetae.com (E-ISSN 2250-2459, Scopus Indexed, ISO 9001:2008 Certified Journal, Volume 11, Issue 12, December 2021)

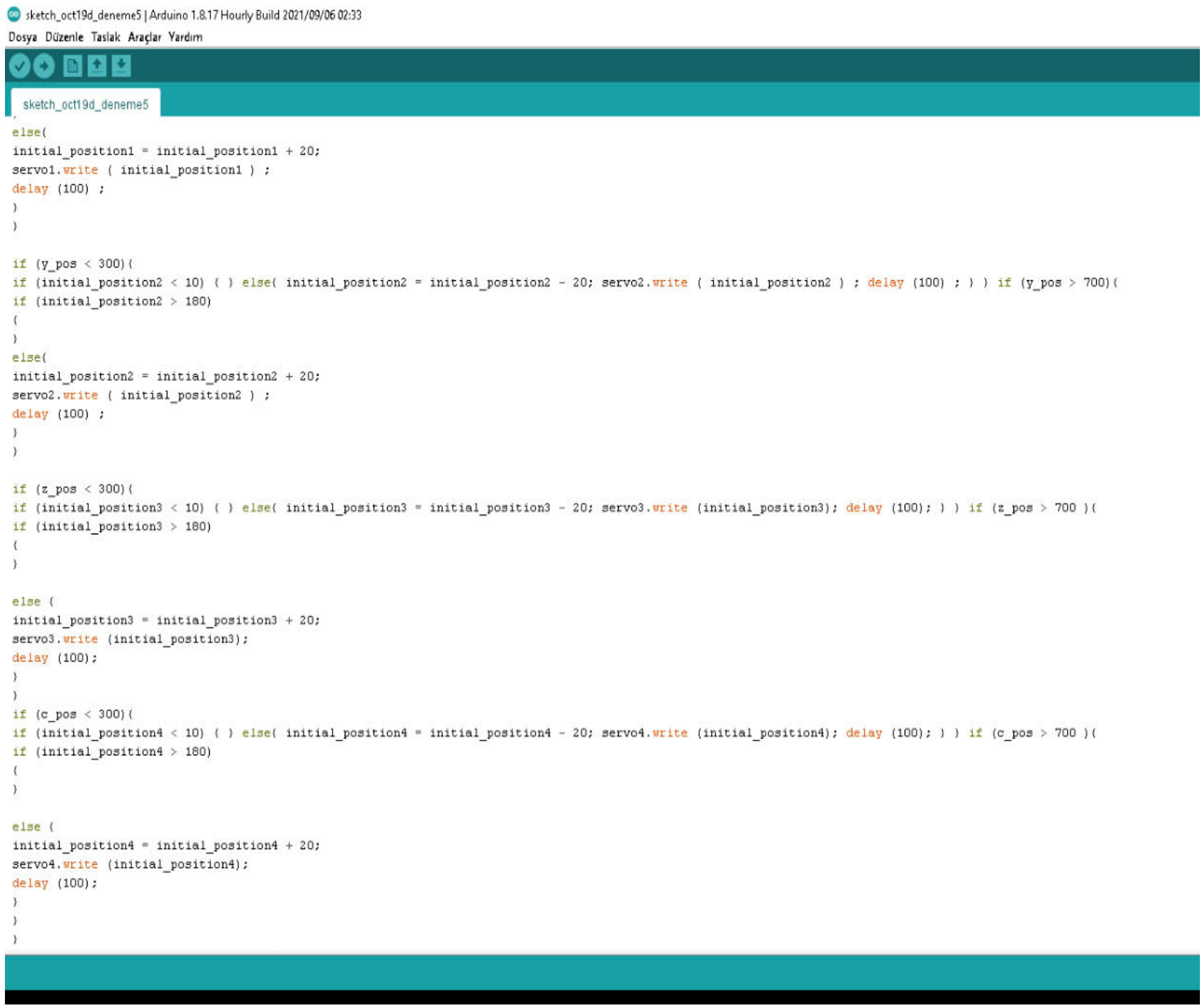

Figure 4. Ardunio Codes 


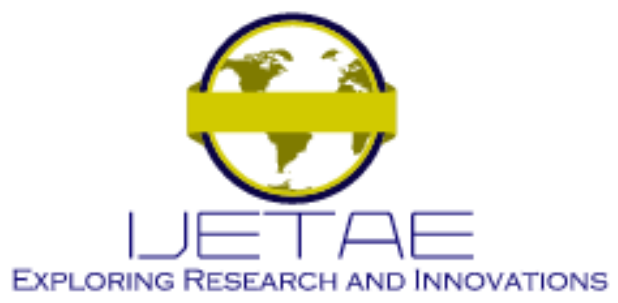

International Journal of Emerging Technology and Advanced Engineering

Website: www.ijetae.com (E-ISSN 2250-2459, Scopus Indexed, ISO 9001:2008 Certified Journal, Volume 11, Issue 12, December 2021)

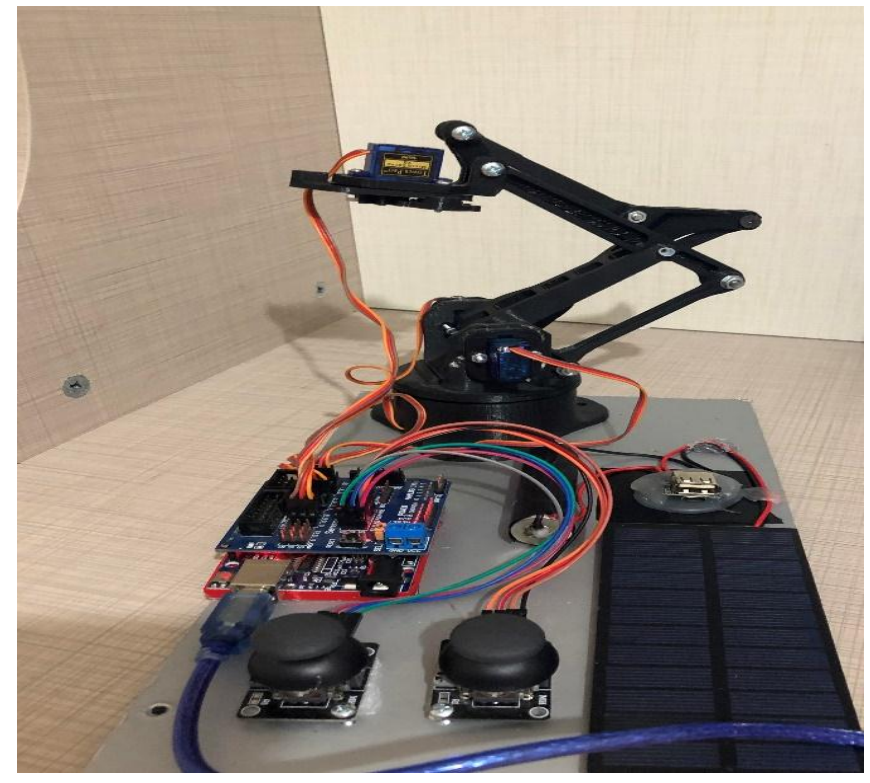

Figure 5. Three-Dimensional Rotation

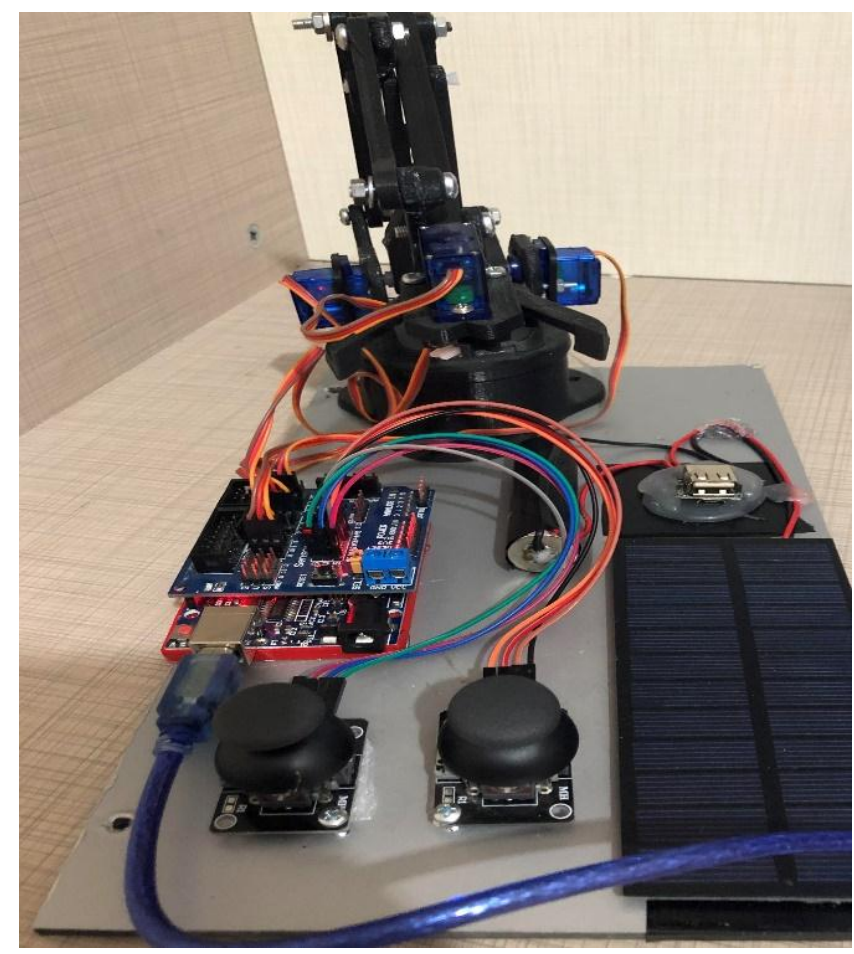

Figure 6. Manipulator Mechanical Clamp

\section{CONCLUSION \& SUGGESTION}

In addition to meeting the needs, being able to manufacture quality products cheaply, reducing the workload, minimizing the error automation system is needed. While the robot arms were used as auxiliary elements in places where human power was not sufficient at first, they were made to work spontaneously without the need for human power day by day. This research a modeling study has been carried out for the production of solar powered arduino robot arm. In this context this study is an example of construction manufacturing and computer interaction. The designed 3D robot arm works on the vertical axis while moving in the horizontal plane with 4 servo motors. Robotic systems; it was formed as a result of the cooperation of Mechatronics Engineering, Mechanical Engineering, Electrical-Electronics Engineering and Computer Engineering.

In the first stage, literature review was made and information about the usage areas and purposes of the robot arm was obtained. In this project work, 4 servo and 1 step motor robot arm, which can be used as a mobile robot, are designed and it is aimed to be developed. In the project, an arduino uno card was used to connect the motion of the servo motors of the robot arm and the interface program. When the literature review is done, it has been determined that robot arm production is frequently made; but in this research, a solar panel was added to the setup. Contribution of this plugin; the solar panel converts these photons into direct current electrons thus the incoming energy is stored. If the motors of the required size are selected, this robot arm assembly can be used as an automation system in various industrial areas.

\section{REFERENCES}

[1] Altuntop, N., Erdemir, D. 2012. Investigating the Development of Solar Energy Systems Market in Turkey, International $100 \%$ Renewable Energy Conference and Exhibition- IRENEC 2012, İstanbul.Ding,

[2] Aydogan, B. (2016). Arduıno ile robot kol kontrolü. Karabuk University Faculty of Engineerıng Mechatronic Engineerıng, Karabuk, Turkey. Unpublished Graduation Thesis. Tavel, P. 2007 Modeling and Simulation Design. AK Peters Ltd.

[3] Browne, B. A. (1998). Gender stereotypes in advertising on children's television in the 1990s: A cross-national analysis. Journal of Advertising, 27(1), 83-96. https://doi.org/10.1080/00913367.1998.10673544Forman, G. 2003. An extensive empirical study of feature selection metrics for text classification. J. Mach. Learn. Res. 3 (Mar. 2003), 1289-1305. 


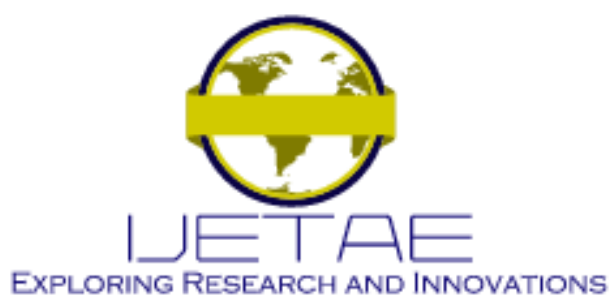

International Journal of Emerging Technology and Advanced Engineering

Website: www.ijetae.com (E-ISSN 2250-2459, Scopus Indexed, ISO 9001:2008 Certified Journal, Volume 11, Issue 12, December 2021)

[4] Celebi, A. , Korkmaz, A., Yılmaz, T. \& Tosun, H. (2019). 3 boyutlu yazıcı ile 6 eksenli robot kol tasarım ve imalatı. International Journal of 3D Printing Technologies and Digital Industry, 3 (3), 269278. Retrieved

from https://dergipark.org.tr/tr/pub/ij3dptdi/issue/51591/657538.

[5] Creswell, J. W., \& Creswell, J. D. (2017). Research design: Qualitative, quantitative, and mixed methods approaches. Sage publications

[6] De Silva, D. (1987). Reactions to Robots, Engineering: April.
[7] Nakamura, S. (1991) Applied Numerical Methods with Software. Prentice-Hall International Editions, Upper Saddle River.

[8] Novita, M., Marlina, D., Kusumo, H., Anwar, T. and Ogasawara, K. (2021). Prediction on the multiplet energy diagram of $\alpha$-Al2O3: Mn4+ under pressure. Journal of Physics: Conference Series, Volume 1869, 2nd Annual Conference of Science and Technology (ANCOSET 2020), Malang, Indonesia

[9] Kumar, S., Rani, K. \& Banga, V. (2017). Robotic Arm Movement Optimization Using Soft Computing. International Journal of Robotics and Automation 6 (1), 1-14. DOI: 10.11591/ijra.v6i1. pp1-14 